\title{
Corrosion Behavior of Pure Cr, Ni, and Fe Exposed to Molten Salts at High Temperature
}

\author{
O. Sotelo-Mazón, ${ }^{1}$ C. Cuevas-Arteaga, ${ }^{1}$ J. Porcayo-Calderón, ${ }^{1}$ \\ V.M. Salinas Bravo, ${ }^{2}$ and G. Izquierdo-Montalvo ${ }^{2}$ \\ ${ }^{1}$ FCQeI-CIICAp, Universidad Autónoma del Estado de Morelos, Avenida Universidad 1001, Colonia Chamilpa, \\ 62210 Cuernavaca, MOR, Mexico \\ ${ }^{2}$ Instituto de Investigaciones Eléctricas, Reforma 113, Colonia Palmira, 62490 Cuernavaca, MOR, Mexico
}

Correspondence should be addressed to C. Cuevas-Arteaga; ccuevas@uaem.mx

Received 23 January 2014; Revised 7 April 2014; Accepted 14 April 2014; Published 19 May 2014

Academic Editor: Markku Leskela

Copyright (C) 2014 O. Sotelo-Mazón et al. This is an open access article distributed under the Creative Commons Attribution License, which permits unrestricted use, distribution, and reproduction in any medium, provided the original work is properly cited.

Corrosion resistance of pure $\mathrm{Fe}, \mathrm{Cr}$, and $\mathrm{Ni}$ materials exposed in $\mathrm{NaVO}_{3}$ molten salt at $700^{\circ} \mathrm{C}$ was evaluated in static air during 100 hours. The corrosion resistance was determined using potentiodynamic polarization, open circuit potential, and lineal polarization resistance. The conventional weight loss method (WLM) was also used during 100 hours. The electrochemical results showed that $\mathrm{Fe}$ and $\mathrm{Cr}$ have a poor corrosion resistance, whereas pure Ni showed the best corrosion performance, which was supported by the passive layer of $\mathrm{NiO}$ formed on the metallic surface and the formation of $\mathrm{Ni}_{3} \mathrm{~V}_{2} \mathrm{O}_{8}$ during the corrosion processes, which is a refractory compound with a higher melting point than that of $\mathrm{NaVO}_{3}$, which reduces the corrosivity of the molten salt. Also, the behavior of these materials was associated with the way in which their corresponding oxides were dissolved together with their type of corrosion attack. Through this study, it was confirmed that when materials suffer corrosion by a localized processes such as pitting, the WLM is not reliable, since a certain amount of corrosion products can be kept inside the pits. The corroded samples were analyzed through scanning electron microscopy.

\section{Introduction}

The corrosion is the degradation of a material due to the oxidizing environment. Corrosion degradation affects in a negative way the properties of the materials, which must be preserved to some applications [1].

High temperature corrosion was first recognized as a serious problem in 1940 in connection with the degradations of the wall tubes of furnaces present in electrical plants, which generate vapor at high temperatures $\left(600\right.$ to $\left.1100^{\circ} \mathrm{C}\right)$. Since then, the corrosion problem has been observed in furnaces, combustion machines, gas turbines, and waste to energy plants among others. Nevertheless, corrosion problems have been important and have been of popular interest from the 60 s, when serious corrosive attacks occurred in helicopters engines used to rescue people near seacoasts during the Vietnam conflict $[2,3]$. Due to the reduction of highgrade fuel and for economic reasons, the use of residual fuel oil was amply utilized, especially in power generation systems. The ashes formed during the combustion process of residual fuel oil contain high concentrations of the elements vanadium, sodium and sulfur, which form some compounds such as $\mathrm{Na}_{2} \mathrm{SO}_{4}$ and $\mathrm{V}_{2} \mathrm{O}_{5}$, and some other complex compounds called sodium vanadyl vanadates [4-7]. Sodium vanadyl vanadates are present as $\mathrm{NaVO}_{3}$ (meta-vanadate), $\mathrm{Na}_{2} \mathrm{~S}_{2} \mathrm{O}_{7}$ (sodium pyro-sulfate), $\mathrm{Na}_{2} \mathrm{O} \cdot \mathrm{V}_{2} \mathrm{O}_{4} \cdot 5 \mathrm{~V}_{2} \mathrm{O}_{5}$ (beta vanadyl vanadate) and $5 \mathrm{Na}_{2} \mathrm{O} \cdot \mathrm{V}_{2} \mathrm{O}_{4} \cdot 11 \mathrm{~V}_{2} \mathrm{O}_{5}$ (gama vanadyl vanadate) among others.

This type of corrosion is called high temperature corrosion by molten salts or hot corrosion [8], occurring on the heated surfaces of superheaters or reheaters, which are between 600 and $650^{\circ} \mathrm{C}$. This type of corrosion is also called vanadium attack, since there is evidence that vanadium contributes mainly to the corrosion of metallic surfaces at high temperatures $[9,10]$. Basically, depending on the superheaters and reheaters design, molten salts can be formed 
on the specific metallic surface areas, producing a high corrosive condition. Also, during the normal combustion process of residual oil, vanadium oxide vapors and alkali metal sulfides can react to form binary systems suffering a eutectic reaction at a relatively low temperature $\left(600^{\circ} \mathrm{C}\right)$ causing that alkaline deposits melt and form a stable electrolyte layer on the metallic surfaces. Vanadium compounds are very stable and corrosive under normal operation conditions of power station boilers [11, 12].

Iron base alloys and nickel base superalloys are very common commercial alloys used for high temperature applications, for instance, in the manufacture of components used for aggressive environmental of gas turbine and vapor generators. The mechanical performance and good corrosion resistance of the alloys (especially that of nickel base) are necessary features to make these materials useful for components such as blades, which are under high temperature in gas turbines of industries, such as that for energy conversion [13]. By the above said, the corrosion study of pure iron, chromium, and nickel materials is very important, since they are the base for stainless steel, mainly the 300 series (austenitic) and superalloy nickel base as Inconel or Hastelloy. On the other hand, chromium is one of the most important alloyed elements, which greatly improves the corrosion resistance of the materials [14].

In this paper, the corrosion resistance of pure chromium, nickel, and iron materials exposed for 100 hours in $\mathrm{NaVO}_{3}$ of at $700^{\circ} \mathrm{C}$ was evaluated. Two electrochemical techniques such as LPR and polarizations curves were applied, together with the measurement of the free corrosion potential. Weight loss method was also applied, making a comparison between the electrochemical and the conventional results. X-ray diffraction analysis of the corrosion products generated during the corrosion attack and microstructural observations by scanning electron microscopy, together with mappings of the main elements of the corrosive systems, helped to determine the corrosion resistance of the pure materials and supported the understanding of corrosion mechanism under high vanadium molten salts.

\section{Materials and Methods}

2.1. Preparation of the Electrodes. High-purity (99.98\%) iron samples, nickel samples (99.8\%), and chromium samples (99.9\%) were made of rectangular bars and cut as small parallelepipeds sized $10 \times 5 \times 5 \mathrm{~mm}$. In order to obtain a defined area and a homogeneous surface, the specimens were ground to 600 grit silicon carbide paper, rinsed with distilled water, degreased with acetone, and dried under a warm air stream. These specimens were the working electrodes, to which one $80 \mathrm{wt} \% \mathrm{Cr}-20 \mathrm{Ni}$ wire (150 mm long, and $1 \mathrm{~mm}$ in diameter) was spot welded. This wire was used as electrical connection between the working electrode and the potentiostat. For isolating the $80 \mathrm{Cr}-20 \mathrm{Ni}$ wire from the molten salts, ceramic tubes were used; the gap between the ceramic tube and the electrical connection wire was filled with refractory cement. The reference electrode and counter electrode were $0.5 \mathrm{~mm}$ platinum wires. In previous research, platinum electrode was tested to assess its stability as a reference electrode under similar experimental conditions considered in the present work, such as mentioned in some reported studies [15].

2.2. Electrochemical Procedure. The procedure in the performance of the electrochemical techniques together with the measurement of the free corrosion potential was similar. The amount of molten salt used for the four techniques in each experiment was $500 \mathrm{mg}$ of $\mathrm{NaVO}_{3} / \mathrm{cm}^{2}$ of the initial exposed area of the different metallic samples, such as what has been reported elsewhere $[15,16]$. The amount of molten salt together with the specimens was placed in a $20 \mathrm{~mL}$ silica crucible. For the three electrochemical measurements, the atmosphere above the melt was static air. Then the silica crucible was set inside an electrical tube furnace to reach the test temperature of $700^{\circ} \mathrm{C}$, which was measured constantly during the tests using a type $\mathrm{K}$ thermocouple and was controlled to $2^{\circ} \mathrm{C}$ with respect to the test temperature. Once the crucible with the corrosive mixture was introduced inside the electrical furnace, the electrochemical cell formed with the reference and counter electrodes, together with the working electrode, was set in the crucible. Before starting the three different electrochemical tests, the electrochemical system was held during 20-30 minutes until the stable state was reached.

2.3. Electrochemical Parameters. In order to determine the corrosion resistance of the three pure materials $(\mathrm{Cr}, \mathrm{Ni}$, and $\mathrm{Fe}$ ) potentiodynamic polarization curves (PC), open circuit potential (OCP), and lineal polarization resistance (LPR) were measured. PC measurements were carried out applying an overpotential from $400 \mathrm{mV}$ to $1500 \mathrm{mV}$ with respect to the corrosion potential at a scan rate of $1 \mathrm{Mv} / \mathrm{s}$. LPR was measured applying an overpotential of $\pm 20 \mathrm{mV}$ with respect to the corrosion potential at the same scan rate as that applied to the polarization curves. The open circuit potential was taken using a platinum wire as the reference electrode. All the electrochemical measurements were made using an ACM Instruments Auto DC potentiostat controlled by a personal computer.

2.4. Procedure for Weight Loss Tests. Standard weight loss tests were also carried out under the same experimental conditions than that for LPR, polarization curves, and open potential circuit tests, following the procedure according to ASTM G31 [17]. In these experiments, two different specimens for each measurement were used. The samples were weighed before exposure by means of an analyticaldigital balance with a precision of $0.0001 \mathrm{~g}$. Ten specimens were totally packed in corrosive mixtures contained in independent silica crucibles, and then they were introduced in an electric furnace in a static air atmosphere. Each twenty hours, two specimens were removed from the furnace until period completion. The corrosion products were removed from the set of two corroded alloys before the final weighing by mechanical and chemical cleaning according to ASTM G1 standard [18]. The mechanical procedure consisted in cleaning the surfaces of specimens in a repetitive way until 
the surfaces were free of corrosion products, being the mass loss determined after each cleaning by weighing the specimens. As it was explained before, the exposure was made by applying duplicate, and when the differences in weight loss at the final weighing was more than $10 \%$, the test was repeated. In this way, the results precision was controlled. Besides, at the last two or three weighing, the specimens were observed by means of an optical microscope, which was useful to determine the remains of corrosion products. In this way, the probability to affect the real weight loss measurement was tried to keep it low. The specimens free of corrosion products were washed with acetone and then weighed using an analytical balance. The evaluation of the corrosion rate was determined as weight loss by means of calculating the difference between the initial and final weight divided by the initial area of specimens for each measure.

2.5. Samples Characterization. In order to determine the kind of corrosion compounds developed during the corrosion process, the corrosion products obtained after cleaning the exposed specimens from the lineal polarization resistance technique were kept for X-ray diffraction analysis (XRD) utilizing a diffractometer operating with $\mathrm{Cu} \mathrm{K} \alpha$ radiation, and results were interpreted using the Powder Diffraction Data File [19]. Also, the cleaned specimens were observed under the optical microscope to examine the morphological surface and determine the type of corrosion attack.

Scanning electron microscopy (SEM) technique was used to characterize the exposed samples from the LPR technique. Such analysis was carried out using a Microspec WDX-3PC system connected to a Zeiss DSM 960 scanning electron microscopy. The specimens exposed for $100 \mathrm{~h}$ to the molten salt were mounted (without descaling) in bakelite, metallographically polished, and the cross section was analyzed to investigate the morphology and distribution of reaction products. Through SEM analysis, an electron image of the metal-scale interface and X-ray mappings of the mean elements of each system were obtained and used to determine the corrosion resistance and type of corrosion attack of the three pure materials.

\section{Results and Discussion}

3.1. Physical Characterization. Figure 1 presents two micrographs of the three types of corroded specimens (chromium, nickel, and iron resp.) exposed to the $\mathrm{NaVO}_{3}$ molten salt during 100 hours. In the case of pure chromium, a particularly generalized corrosion process throughout the surface seems to be observed, where a significant amount of local attacks are present. The local attack is in form of severe pitting, observing around the pits the cathodic areas. Pitting corrosion phenomenon is that in which the material is passivated; afterward, it suffers the rupture of the passive film, generating active zones in small areas with high corrosion rates, where the nucleation and subsequent formation of cavities or pits are present [20], such as what is observed in Figures 1(a) and 1(b) of pure chromium. Pure nickel suffered a mixed corrosion process, in which some zones are corroded in a uniform way and other ones in a localized way. It seems like chromium and nickel corroded in an alike way, but nickel generates much bigger pits and cathodic zones, which suffered uniform corrosion. Also, nickel presents some irregular corroded zones, probably due to the joining of several pits. The corroded image of pure iron presents a generalized corrosion process in form of localized corroded sites (hollows), which seem to have formed due to a severe intergranular corrosion process, with the following grain dropping. The evidence of the revealed grain bodies is present on the entire surface, observing the preferential corrosion at the grain boundaries of the metal. The depth of walls of the grains, which have been released, is evident together with different geometrical forms of the grains, which have also an irregular size between 20 and $130 \mu \mathrm{m}$ approximately.

Figure 2 shows a micrograph of a cross section of the metal-scale interface of the corroded sample of chromium exposed to $\mathrm{NaVO}_{3}$ molten salt at $700^{\circ} \mathrm{C}$ during $100 \mathrm{~h}$ after applying the electrochemical LPR technique. Also X-ray mappings of $\mathrm{Cr}, \mathrm{O}$, and $\mathrm{V}$ are presented. After 100 hours, chromium mapping shows a light layer of chromium related to a light oxygen layer. It can be inferred that initially chromium may have formed a thick and coherent chromium oxide film performing as a passive layer, which was nucleated due to the interaction with the oxidizing species (vanadium and oxygen) to be attacked by severe pitting, such as what has been shown in the corresponding corroded sample of chromium. After that, and once the vanadium was diffused to the metallic surface, the chromium oxide becomes porous due to the chemical interaction (dissolution of $\mathrm{Cr}_{2} \mathrm{O}_{3}$ ) by effect of the corrosive vanadium, forming chromium vanadates, such as what has been determined by XRD analysis (see Figure 3). The previous dissolution of $\mathrm{Cr}_{2} \mathrm{O}_{3}$ left light layers of chromium and oxygen, whereas the formation of $\mathrm{CrVO}_{3}$ allows to see a thick layer of vanadium (see Figure 2), which probably contains a great amount of nonreactive vanadium. Due to the presence of severe pitting developed by pure chromium, it is possible that some traces of chromium oxide had been kept inside the pits, which explain the amount of oxygen seen in the interior of the sample, just below the metallic surface. Unfortunately, the high concentration of vanadium as a thick layer over the metallic surface does not help to visualize more clearly the chromium layer related to the still present chromium oxide. In fact, those materials, suffering pitting corrosion, present degraded passive films once the localized attack has been fully developed.

Figure 4 shows a micrograph of a cross section of the metal-scale interface of the corroded nickel exposed to $\mathrm{NaVO}_{3}$ molten salt at $700^{\circ} \mathrm{C}$ during $100 \mathrm{~h}$ after applying the electrochemical LPR technique. X-ray mappings of nickel, oxygen, and vanadium are also presented. According to the nickel mapping, there is a medium concentrated $40 \mu \mathrm{m}$ nickel layer over the metal surface, which is related to the oxygen mapping, confirming the presence of nickel oxide, such as what was also found in XRD analysis (Figure 5). The presence of vanadium mixed with the nickel oxide is evident too, since a thick layer of vanadium is shown through the corresponding mapping, observing that vanadium has diffusing until the metal-corrosion products interface. In 


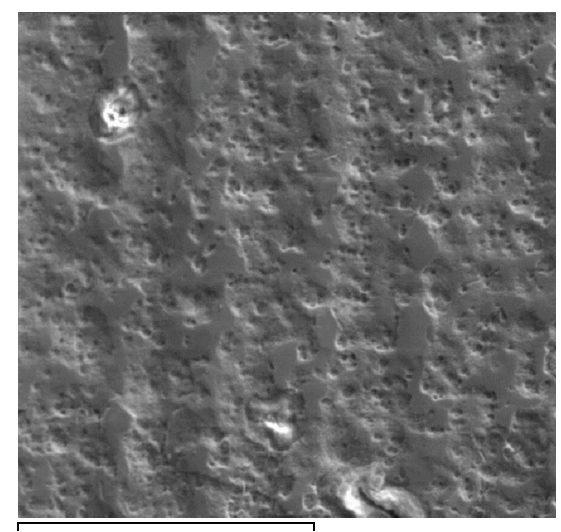

$80 \mu \mathrm{m}$

Chromium

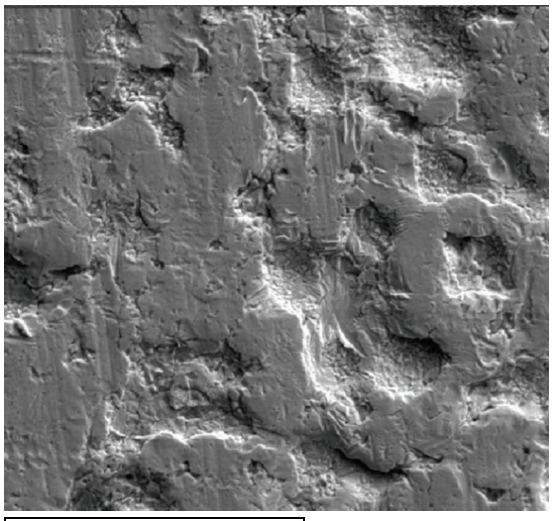

$80 \mu \mathrm{m}$

Nickel

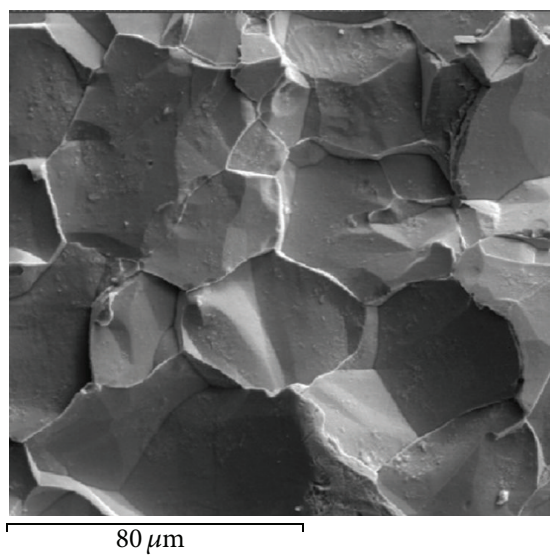

Iron

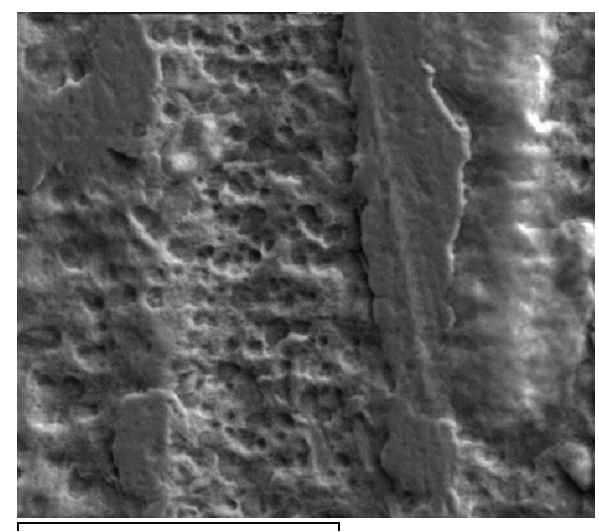

$40 \mu \mathrm{m}$

Chromium

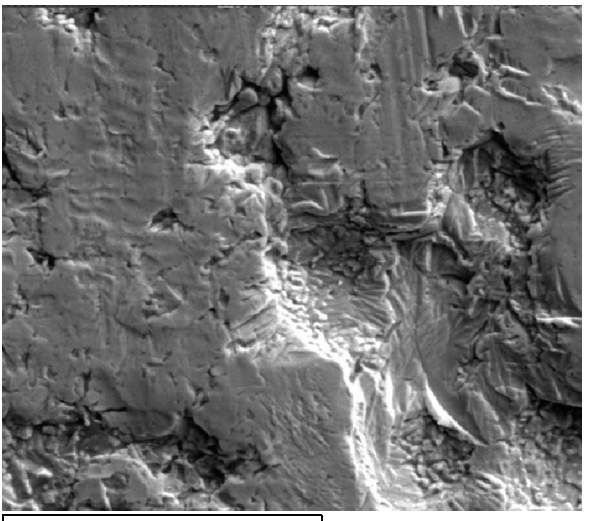

$40 \mu \mathrm{m}$

Nickel

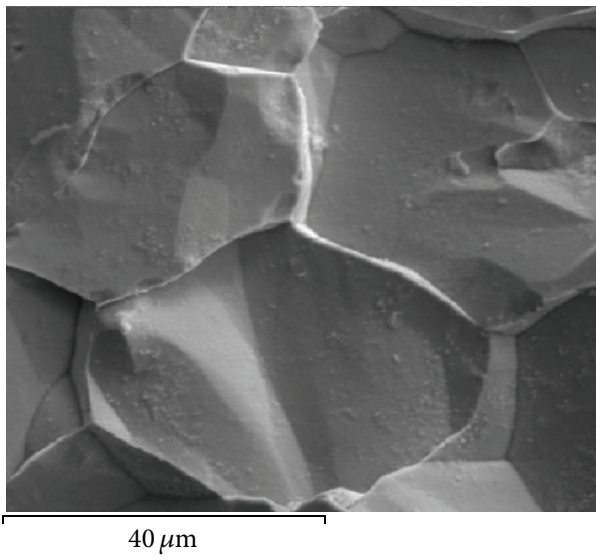

Iron

FIgURE 1: Micrographs of the cleaned pure chromium, pure nickel, and pure iron after being exposed to $\mathrm{NaVO}_{3}$ for 100 hours at $700^{\circ} \mathrm{C}$.

fact, the nickel-oxygen layers seem to be porous with several empty routes through which vanadium diffuses to reach the metal surface. After that, vanadium has extended through the surface, evidencing the presence of nickel vanadates in form of $\mathrm{Ni}_{3} \mathrm{~V}_{2} \mathrm{O}_{8}$ and $\mathrm{Ni}_{2} \mathrm{O}_{2} \mathrm{O}_{7}$ and sodium vanadates (see $\mathrm{XRD}$ spectrum in Figure 5). Even though the mapping of sodium is not shown in this paper, it can be said that sodium was presented together with the vanadium as a lighter layer, such as what was confirmed by its corresponding mapping. Considering the fact that nickel suffered pitting corrosion, it is adduced that, at the starting of the corrosion process, nickel was oxidized; afterward, an adherent and coherent nickel oxide was formed as a passive film, which was cracked, with the consecutive formation of pits. It seems to be that nickel developed a thinner and compact oxide layer with respect to that developed by chromium, although the pits presented 

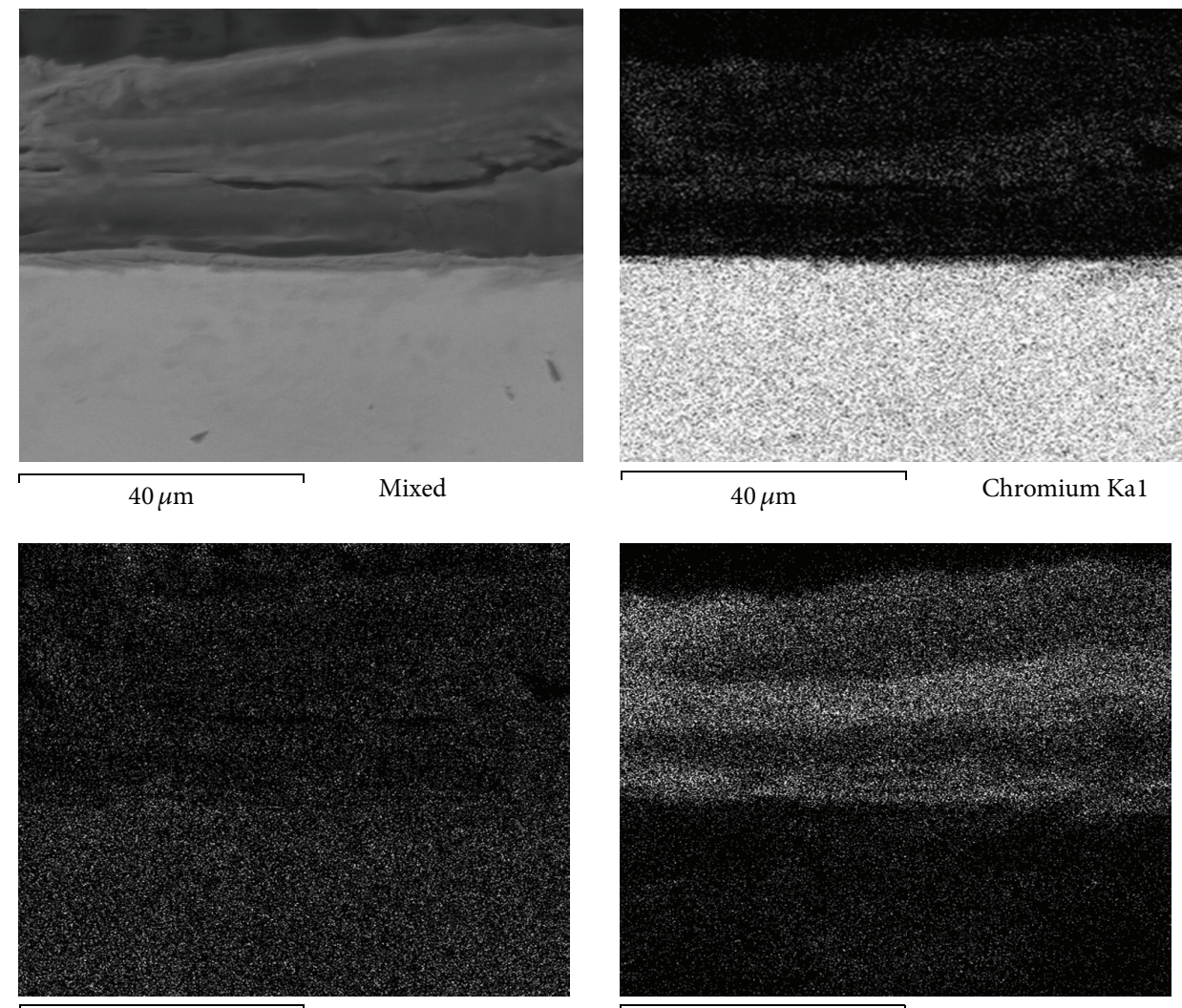

$40 \mu \mathrm{m}$

Oxygen Ka1

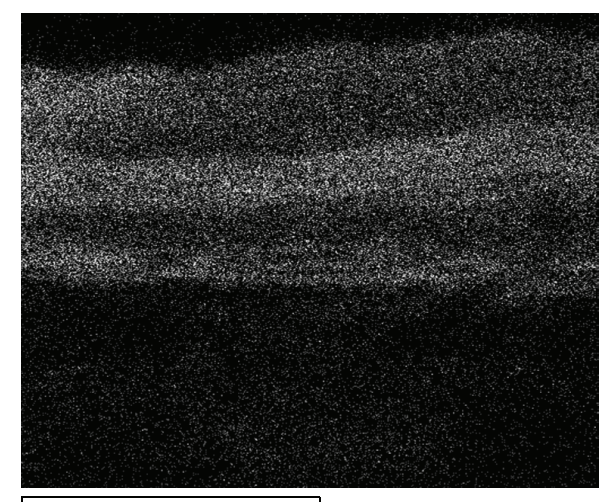

$40 \mu \mathrm{m}$

Vanadium Ka1

FIGURE 2: Electron image of the metal-scale interface and $\mathrm{X}$-ray mappings of $\mathrm{Cr}$, $\mathrm{O}$, and $\mathrm{V}$ when pure metal chromium was exposed to $\mathrm{NaVO}_{3}$ at $700^{\circ} \mathrm{C}$ during 100 hours.

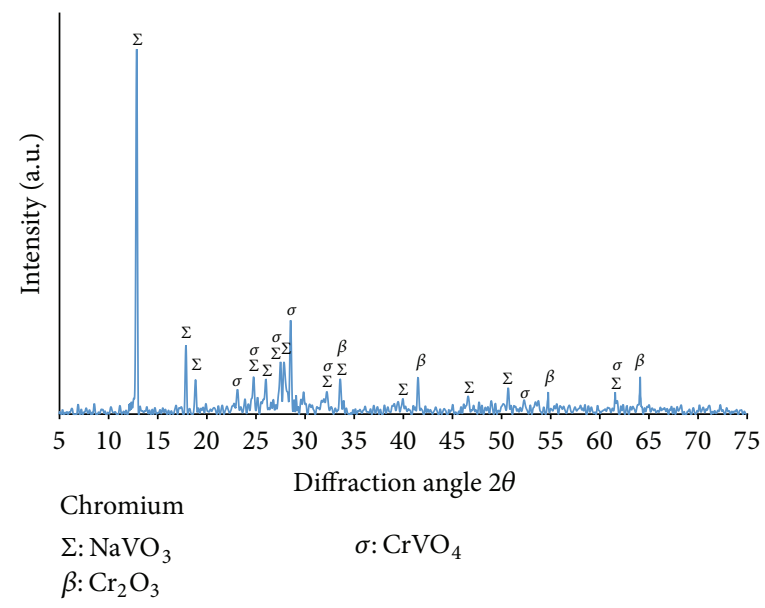

FIGURE 3: X-ray diffraction results of corrosion products of chromium exposed to $\mathrm{NaVO}_{3}$ at $700^{\circ} \mathrm{C}$ during 100 hours.

by nickel were bigger than those presented by chromium; nevertheless, the cathodic zones were also bigger, which suffered a uniform corrosion; therefore, it could be possible that the global corrosion rate be lesser than that of chromium. On the other hand, the dissolution rate of nickel oxide seems to be lower than its formation rate, since the nickel oxide layer is yet well defined after 100 hours of exposure. The most important features of nickel and its alloys with respect to the corrosion resistance in molten salt have been seen in high contain of vanadium and low sodium molten salts; nevertheless, in high sulfates molten salts they have not had good performance. For this reason, it is preferable to use alloys with low content in nickel and reach in iron $[21,22]$.

Figure 6 presents the cross section of the interface of ironcorrosion products, together with the mappings of $\mathrm{Fe}, \mathrm{O}$, and V. This analysis was made from the samples obtained 

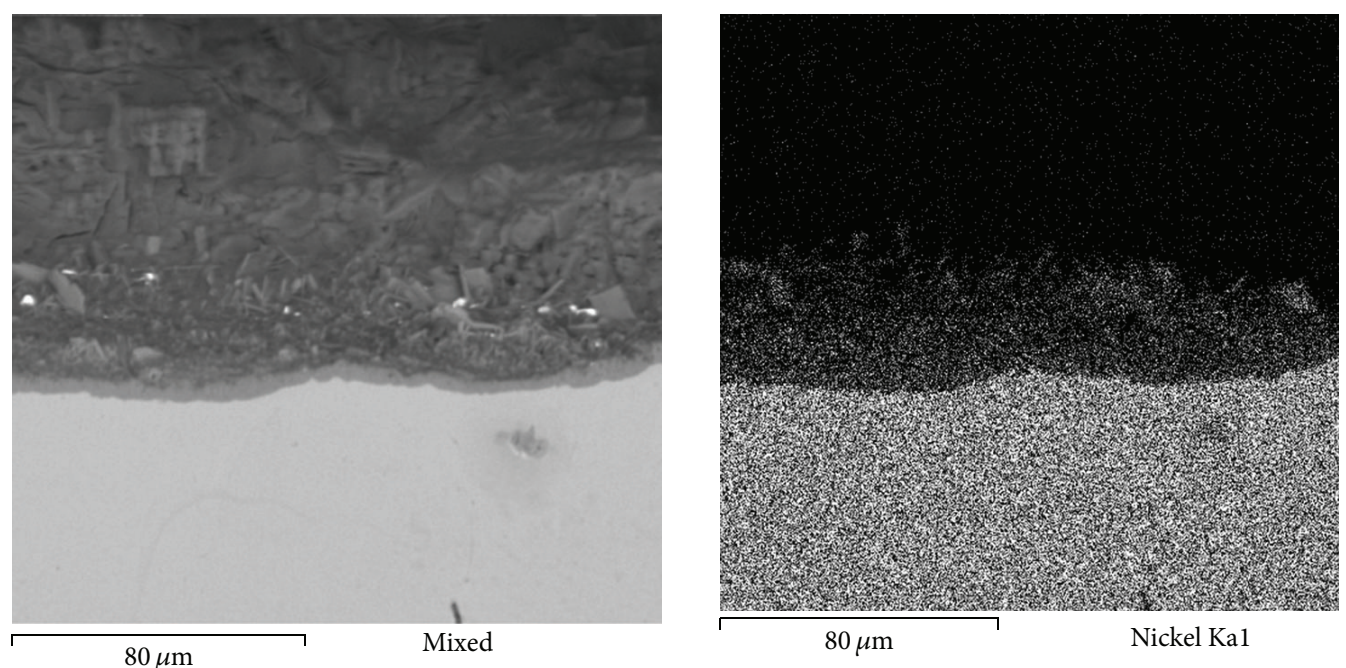

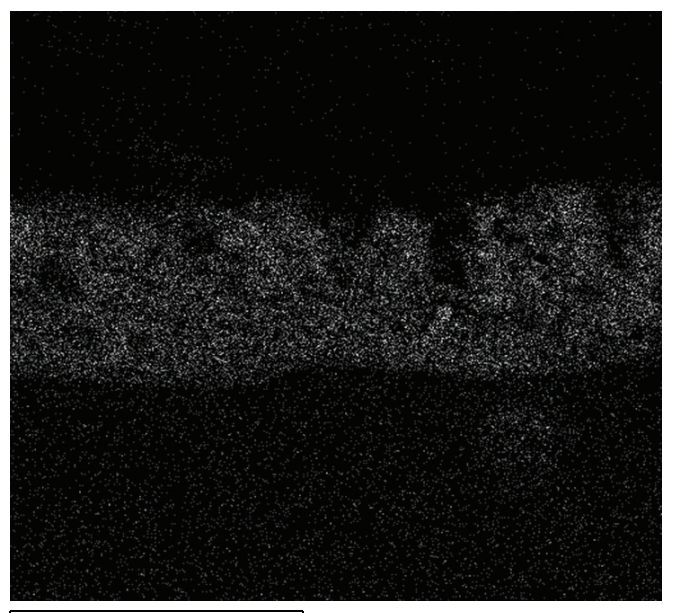

$80 \mu \mathrm{m}$

Oxygen Ka1

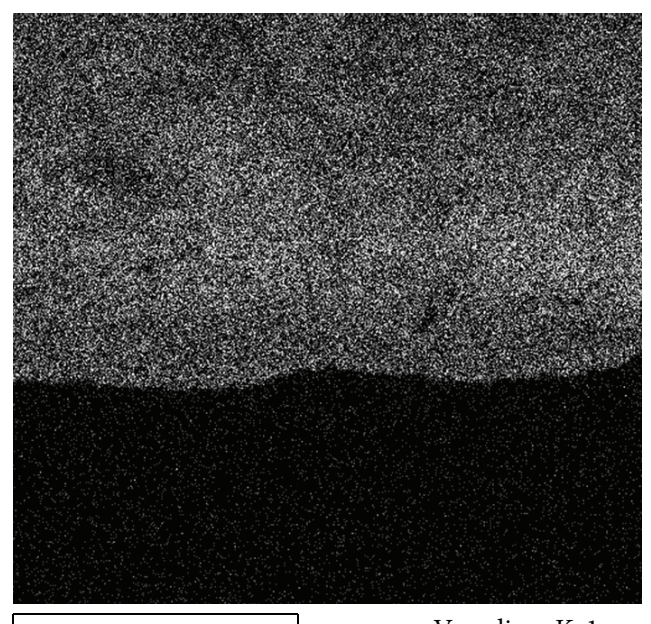

$80 \mu \mathrm{m}$

Vanadium Ka1

FIGURE 4: Electron image of the metal-scale interface and $\mathrm{X}$-ray mappings of $\mathrm{Ni}, \mathrm{O}$, and $\mathrm{V}$ when pure metal nickel was exposed to $\mathrm{NaVO}_{3}$ at $700^{\circ} \mathrm{C}$ during 100 hours.

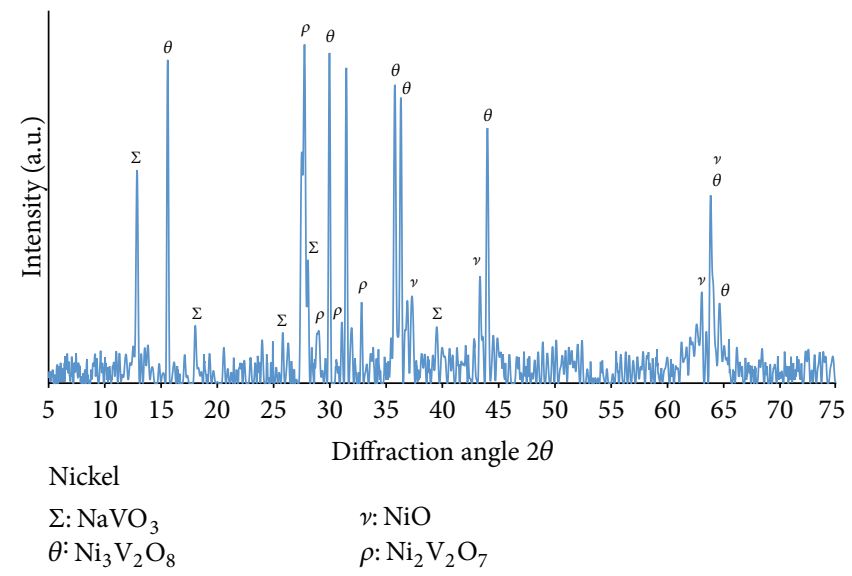

FIGURE 5: X-ray diffraction results of corrosion products of nickel exposed to $\mathrm{NaVO}_{3}$ at $700^{\circ} \mathrm{C}$ during 100 hours. 

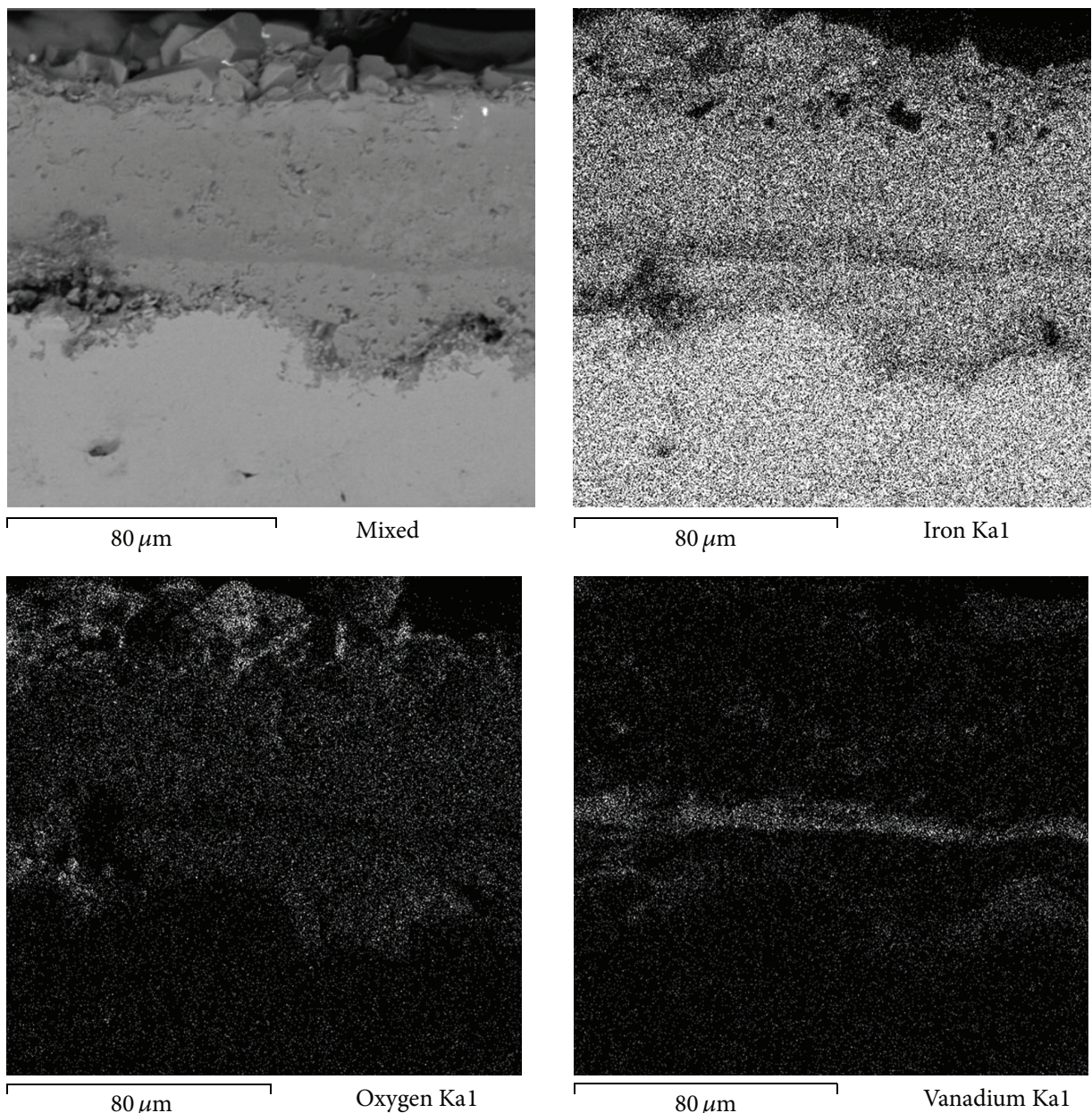

Figure 6: Electron image of the metal-scale interface and $\mathrm{X}$-ray mappings of $\mathrm{Fe}, \mathrm{O}$, and $\mathrm{V}$ when pure metal iron was exposed to $\mathrm{NaVO}_{3}$ at $700^{\circ} \mathrm{C}$ during 100 hours.

after exposure to $\mathrm{NaVO}_{3}$ at $700^{\circ} \mathrm{C}$ applying the LPR electrochemical technique. Figure 7 shows the XRD resulting from the corrosion products of the sample exposed to obtain the potential measurements during 100 hours. Accordingly, with the mapping of Fe after 100 hours, it is stated that this material was not able to develop a protective layer; instead, a thick and porous layer of $120 \mu \mathrm{m}$ was observed. The corrosion process was presented forming a heterogeneous metal-scale interface, seeing that the vanadium molten salt diffusing until the metallic surface to react with the iron oxides, which according to the XRD results were of two types: $\mathrm{Fe}_{2} \mathrm{O}_{3}$ and $\mathrm{FeO}$. These oxides were dissolved by vanadium forming two iron metavanadates $\mathrm{FeVO}_{4}$ and $\mathrm{FeV}_{2} \mathrm{O}_{4}$, which seem to be located along the thick layer and also far away the interface metalcorrosion products as big crystals. The mapping of vanadium shows a $20 \mu \mathrm{m}$ well-defined layer, which outlines the metalscale interface, which is visible in the micrographs too. Below this interface (inside iron), certain amount of vanadium in a disperse way, drawing the same outline than oxygen. Taking into account the intergranular and grain dropping suffered by iron and the oxidizing species of this system (oxygen and vanadium), It can be inferred that oxygen diffused until the grain boundaries producing intergranular corrosion by oxidation with the posterior grain dropping. Vanadium could also diffuse in a minor extend through the same routes than oxygen, that is why the presence of vanadium in some sites occupied by oxygen. Vanadium could also diffuse in a minor extend through the same routes than oxygen, that is why its presence in some places than oxygen. Due the high oxidation suffered by iron (the oxide iron layer is much larger than that for chromium and nickel), a significant depletion of this material is expected, that is why oxygen diffused inside the iron and provoked the intergranular oxidation and grain dropping.

3.2. Electrochemical Results. Figure 8 shows the potentiodynamic polarization curves obtained of the chromium, nickel, and iron pure metals evaluated in sodium metavanadate $\left(\mathrm{NaVO}_{3}\right)$, at $700^{\circ} \mathrm{C}$ in static air at a scan rate of $1 \mathrm{mV} / \mathrm{s}$. From the polarization curves, $\mathrm{Cr}$ exhibits an active corrosion behavior and just at positive potentials reaches passivation, which is in accordance with the passivation required for suffering pitting corrosion, such as observed in Figure 1(a). 


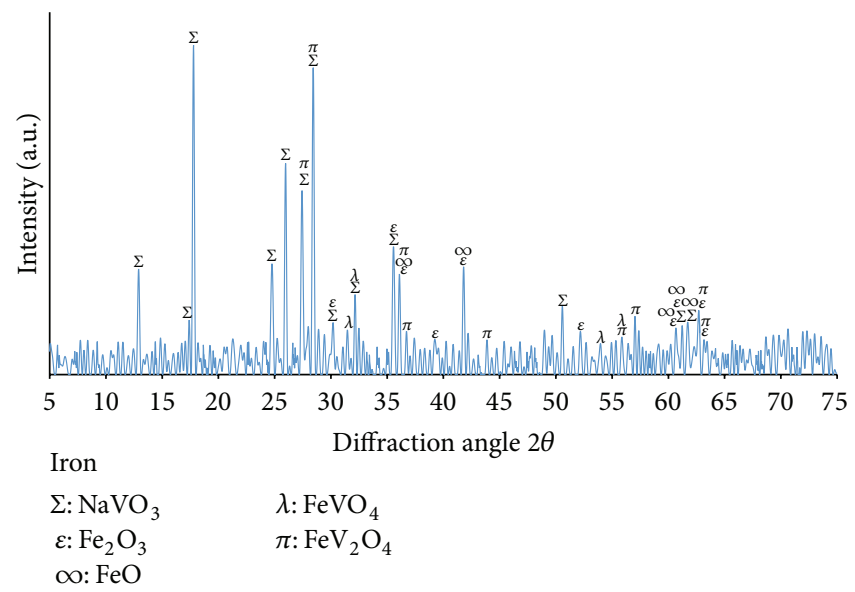

FIGURE 7: X-ray diffraction results of corrosion products of iron exposed to $\mathrm{NaVO}_{3}$ at $700^{\circ} \mathrm{C}$ during 100 hours.

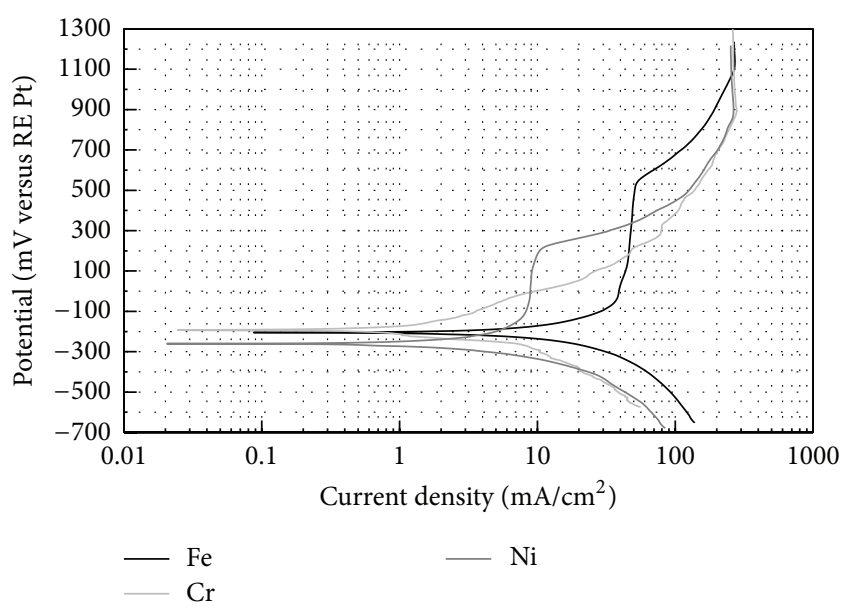

FIGURE 8: Potentiodynamic polarization curves of $\mathrm{Cr}, \mathrm{Ni}$, and $\mathrm{Fe}$ obtained under the exposure in $\mathrm{NaVO}_{3}$ at $700^{\circ} \mathrm{C}$ in static air.

Fe showed a corrosion potential close to that for $\mathrm{Cr}$, and a large passive zone at $150 \mathrm{mV}$ above its corrosion potential (from -50 to $550 \mathrm{mV}$ ). It is important to point out that this apparent passivation could be due to the rapid growth of the corrosion products layer over its surface, which was broken to let the oxygen diffuse until the interior of the substrate producing severe intergranular corrosion, which produced grain dropping. Also, the presence of vanadium mixed with the iron oxide becomes the initial iron oxide in a porous layer, heterogeneous, and not-protective layer. Nickel showed the most active corrosion potential with a passive behavior from -100 to $220 \mathrm{mV}$, which was in agreement with the way in which this material was corroded (deep pitting). Accordingly, with $\mathrm{XRD}$ results, it is stated that through anodic reactions $\mathrm{Fe}^{3+}, \mathrm{Cr}^{3+}$, and $\mathrm{Ni}^{2+}$ anions were formed, while through the cathodic reactions oxygen was reduced to $\mathrm{O}^{2-}$, and the cation $\mathrm{V}^{5+}$ was reduced to $\mathrm{V}^{4+}$. Taking into account the above reactions, Pantony and Vasu [23] proposed a hot corrosion mechanism for metals in vanadium salts, which involves an
TABLE 1: Electrochemical parameters from potentiodynamic polarization curves for $\mathrm{Cr}, \mathrm{Ni}$, and $\mathrm{Fe}$.

\begin{tabular}{lcccc}
\hline Materials & $E_{\text {corr }}(\mathrm{mV})$ & $i_{\text {corr }}\left(\mathrm{mA} / \mathrm{cm}^{2}\right)$ & $\beta_{a}$ & $\beta_{c}$ \\
\hline $\mathrm{Cr}$ & -184 & 0.93 & 201 & 124 \\
$\mathrm{Ni}$ & -259 & 2.42 & 450 & 183 \\
$\mathrm{Fe}$ & -202 & 8 & 300 & 243 \\
\hline
\end{tabular}

interdependent and sequential diffusion of oxygen and other species from the gaseous atmosphere or from the molten salts to the metallic surface or to the interior of metal, and the diffusion of corrosion products (metallic ions generated from the oxidation reaction) to the outside (scales present far away of the metallic surface). In the present case, the corrosion mechanism involves the diffusion of oxygen to the interior of the metal and vanadium species to the surface, and the diffusion of metallic species to the scales, where a high concentration of $\mathrm{NaVO}_{3}$ is present and the metallic oxides are dissolved and become porous.

In Table 1, the electrochemical parameters from the polarization curves are presented for the three studied pure metals. It is observed that $\mathrm{Fe}$ showed the highest corrosion rate $\left(i_{\text {corr }}=8 \mathrm{~mA} / \mathrm{cm}^{2}\right)$, which is in agreement with the severe intergranular and grain dropping suffered by iron, which produces a high loss mass. Even though chromium did not present a passive zone, from XRD results, a $\mathrm{Cr}_{2} \mathrm{O}_{3}$ layer was formed, so that a lowest corrosion rate was obtained $\left(0.93 \mathrm{~mA} / \mathrm{cm}^{2}\right)$. Nickel presented a higher corrosion rate compared to chromium, but its passive behavior evidenced by its corresponding curves can help in long term exposures. Also, due to the fact that corrosion attack was by larger pits, a major corrosion rate was expected.

According to the potentiodynamic polarization curves, it is observed that the corrosion resistance of the studied materials is in the next descendent order: $\mathrm{Cr}>\mathrm{Ni}>\mathrm{Fe}$; nevertheless, it is important to point out that potentiodynamic polarization curves just indicate a short term behavior (just when the corrosive system reaches the stable state); for that reason, and in order to get a most real behavior, long 


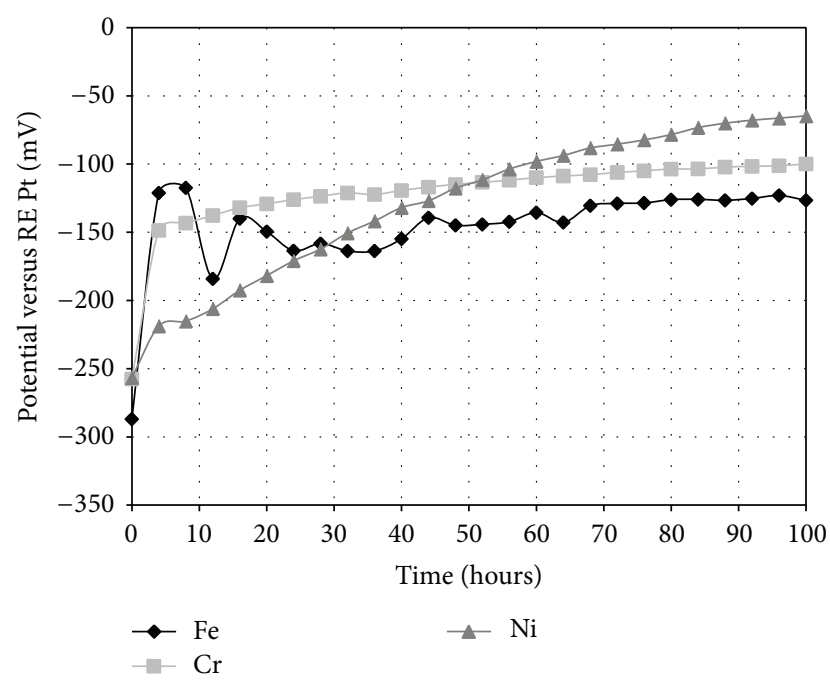

Figure 9: Corrosion potential of $\mathrm{Cr}, \mathrm{Ni}$, and Fe exposed to $\mathrm{NaVO}_{3}$ at $700^{\circ} \mathrm{C}$ in static air.

term evaluations were made applying the lineal polarization resistance technique during 100 hours of exposure.

The chemical interaction between the metallic materials with the environment is fundamental in the understanding of the stability of corrosion process. A simple way to study the formation of protective and passive films of the materials in a specific corrosive medium is to measure the corrosion potentials in time. A high potential (in positive direction) usually indicates the formation of protective films; a stable potential indicates that the passive film keeps protective probable in its original condition. A decrease in potential indicates the broken and dissolution or no formation of a protective film [24]. Given that the behavior of the potential of a material during a corrosive process states the condition or changes of the metallic oxides, which plays an important role in the corrosion resistance of the materials, their measurements are quiet significant.

Figure 9 shows the variation of the corrosion potential during $100 \mathrm{~h}$ of chromium, nickel, and iron measured during $100 \mathrm{hr}$. A sharp increase in $E_{\text {corr }}$ in the first few hours of immersion is observed, which indicates that the three materials tended to form a passive layer to protect them from the corrosive medium. After that, in the case or iron, $E_{\text {corr }}$ showed fluctuations until 68 hours of immersion, with the rest of the time being kept practically constant. This behavior indicates that the passive film of iron was breaking and regenerating constantly until 68 hours; after that, it got some stability. Nevertheless, and taking into account SEM results (Figures 6 and 7), this layer becomes a porous layer letting the oxygen and vanadium diffuse through it; that is probable why the corrosion potential is the lowest (active) with respect to that of chromium and nickel. With respect to chromium, $E_{\text {corr }}$ increased smoothly and constantly until the end of immersion; this behavior indicates the continuous formation of a passive layer. Nickel showed a similar behavior than that of chromium, but with a higher acceleration, and at the end of the exposure $E_{\text {corr }}$ was the nobler; this behavior also

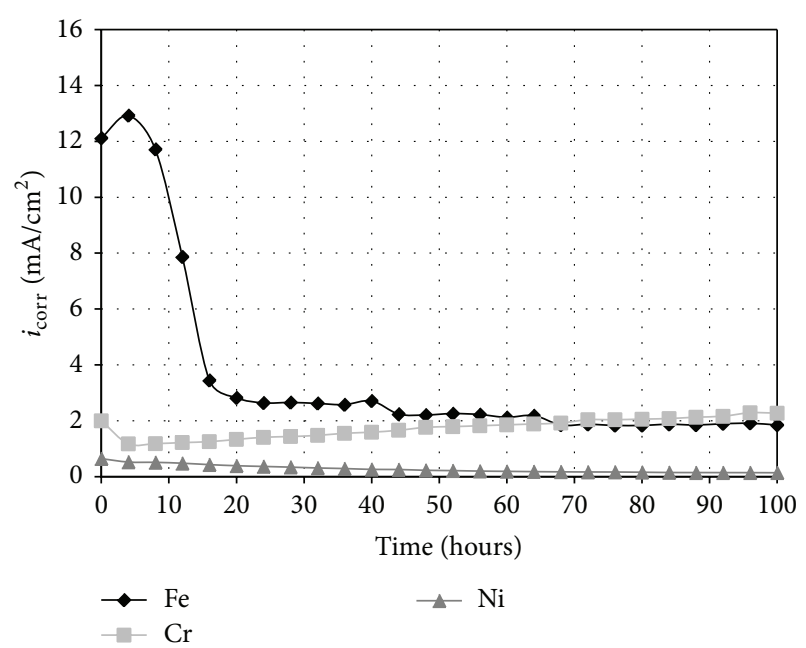

Figure 10: Current density corrosion $\left(i_{\text {corr }}\right)$ for $\mathrm{Cr}, \mathrm{Ni}$, and $\mathrm{Fe}$ exposed to $\mathrm{NaVO}_{3}$ at $700^{\circ} \mathrm{C}$ in static air.

indicates the tendency in the constant formation of a passive layer. According to the open circuit potential, the corrosion resistance of the studied materials was in the falling order $\mathrm{Ni}>$ $\mathrm{Cr}>\mathrm{Fe}$, which is anticipated, since iron suffered the worst type of corrosion.

Figure 10 shows the variation of the corrosion rate $\left(i_{\text {corr }}\right)$ of $\mathrm{Cr}, \mathrm{Ni}$, and $\mathrm{Fe}$ in $\mathrm{NaVO}_{3}$ at $700^{\circ} \mathrm{C}$ for 100 hours. These results were obtained from the measurements of the lineal polarization resistance, calculating $i_{\text {corr }}$ with the following equation:

$$
i_{\text {corr }}=\frac{b_{a} b_{c}}{2.303 R_{p}\left(b_{a}+b_{c}\right)} .
$$

$R_{p}$ is the polarization resistance; $b_{a}$ and $b_{c}$ are the anodic and cathodic Tafel slopes reported in Table 1 . Figure 10 shows the tendency of $i_{\text {corr }}$ of the different studied materials, being in accordance with $E_{\text {corr }}$ from Figure 9. Iron presented the highest initial values of $i_{\text {corr }}\left(12-13 \mathrm{~mA} / \mathrm{cm}^{2}\right)$; subsequently until the 16 hours, it decreased rapidly to $3 \mathrm{~mA} / \mathrm{cm}^{2}$; after that, until the end of the test, $i_{\text {corr }}$ kept decreasing lightly reaching the value of $2 \mathrm{~mA} / \mathrm{cm}^{2}$. It is probable that, from the beginning, the intergranular oxidation and grain dropping were presented. Chromium shows a decrease of $i_{\text {corr }}$ during the first 4 hours of immersion, from 2.0 to $1.5 \mathrm{~mA} / \mathrm{cm}^{2}$, when the passive layer was formed. After that, the passive film started to break and pitting corrosion appeared, increasing $i_{\text {corr }}$ to $2.3 \mathrm{~mA} / \mathrm{cm}^{2}$ for the rest of the exposure time. Regarding nickel, $i_{\text {corr }}$ was the lowest one, with a constant tendency to diminish from 0.65 to $0.15 \mathrm{~mA} / \mathrm{cm}^{2}$ until the end of the test, which is in accordance with its corresponding polarization curve and the way in which this material was corroded, since, even though it suffered pitting corrosion, there were large zones suffering uniform corrosion. According to the behavior of $i_{\text {corr }}$, it is possible to state that the corrosion resistance of the pure materials in the decreasing order was $\mathrm{Ni}>\mathrm{Cr}>\mathrm{Fe}$, 


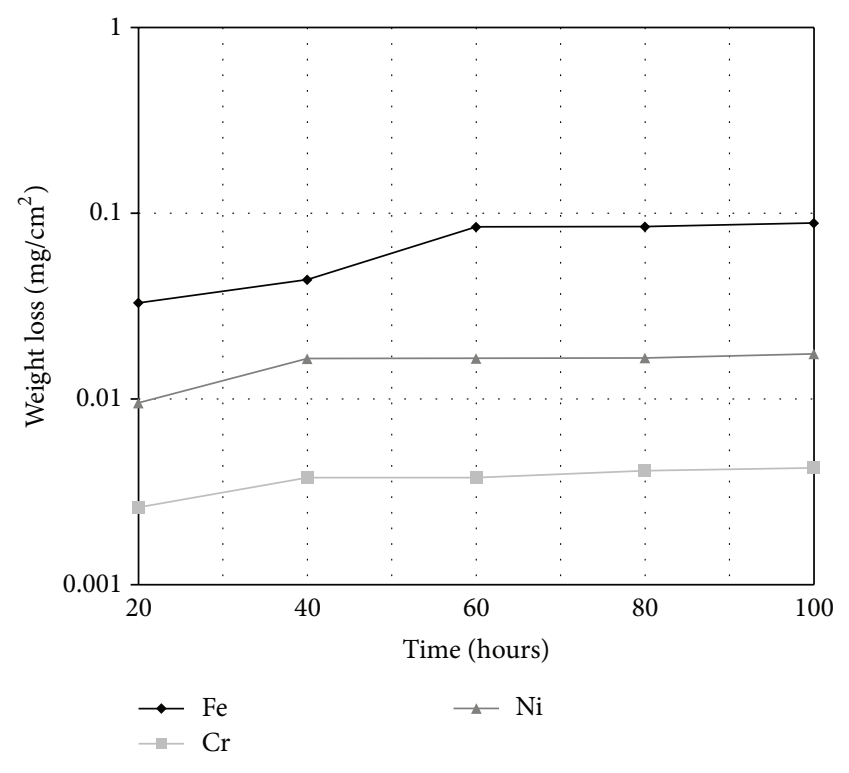

FIgUre 11: Weight loss for $\mathrm{Cr}, \mathrm{Ni}$, and Fe exposed to $\mathrm{NaVO}_{3}$ at $700^{\circ} \mathrm{C}$ in static air.

which is in agreement with the open circuit potential behavior also.

3.3. Weight Loss Method Results. The weight loss measurements of chromium, nickel, and iron are presented in Figure 11. Whereas $i_{\text {corr }}$ is an instantaneous measurement, weight loss method gives a cumulative measure of the corrosion rate. In this case, it is observed that during the first 40 hours the three materials increase their weight loss, behavior extended until the 60 hours. After that and until the end of the test, the values of weight loss are practically constant with a slight increase. Making a comparison, it is clear that iron lost the major weight during the exposure in $\mathrm{NaVO}_{3}$ molten salt, which is in agreement from the electrochemical technique and weight loss method. Nevertheless, there is a discrepancy between the results from both techniques with respect to chromium and nickel, even having the same order of magnitude. This difference could be due to two facts. By one hand, the Stern-Geary equation applied to LPR data has implicit one error, since it must be used just for those systems which are activation controlled; taking into account the Tafel slopes values obtained from the polarization curves, it is evident that, in the three studied cases, diffusion processes are present. By the other hand, the presence of severe pitting corrosion, observed in chromium as a very high density of small pits, makes the cleaning of samples difficult, even applying this method with precision, since, it is highly probable that some corrosion products could keep inside the pits, so that, the weight loss data could be underestimated for chromium. In the case of nickel, which also suffered pitting corrosion, the pits were much bigger with respect to that for chromium (see Figure 1); therefore the cleaning for nickel was easier and accurate.

Also, the difference between the values of the corrosion rate of chromium and nickel is very small, which means
TABLE 2: Melting points of the metallic vanadates formed during the corrosion process of $\mathrm{Cr}, \mathrm{Ni}$, and $\mathrm{Fe}$.

\begin{tabular}{lc}
\hline Vanadates & M.P. $\left({ }^{\circ} \mathrm{C}\right)$ \\
\hline $\mathrm{CrVO}_{4}$ & 810 \\
$\mathrm{Ni}_{3} \mathrm{~V}_{2} \mathrm{O}_{8}$ & 1220 \\
$\mathrm{Ni}_{2} \mathrm{~V}_{2} \mathrm{O}_{7}$ & 820 \\
$\mathrm{FeVO}_{4}$ & 760 \\
\hline
\end{tabular}

that the error due to application of the weight loss method under pitting corrosion conditions is not so significant. Due to the previous explanation, the corrosion rate for chromium should be longer and have the same behavior to that presented from LPR, which in this particular case, can be considered more reliable than the weight loss method.

3.4. Corrosion Mechanism. Through the discussion and interpretation of results made until here, it is important to point out that the electrochemical results provided from the three electrochemical techniques and the conventional weight loss method, together with SEM and XRD analysis, complement each other to elucidate a corrosion mechanism, which leads to a better understanding of the performance of these pure metals in $\mathrm{NaVO}_{3}$ molten salt at high temperature [25]. Therefore, and considering the natural trend of chromium, nickel, and iron to develop a protective oxide on their metallic surfaces, it is possible to establish that the degradation of $\mathrm{Cr}$, $\mathrm{Ni}$, and Fe was throughout the next reactions [26]:

$$
\begin{aligned}
& \mathrm{Fe}_{2} \mathrm{O}_{3}+2 \mathrm{NaVO}_{3}=2 \mathrm{FeVO}_{4}+\mathrm{Na}_{2} \mathrm{O} \\
& \mathrm{Cr}_{2} \mathrm{O}_{3}+2 \mathrm{NaVO}_{3}=2 \mathrm{CrVO}_{4}+\mathrm{Na}_{2} \mathrm{O} \\
& 3 \mathrm{NiO}+2 \mathrm{NaVO}_{3}=\mathrm{Ni}_{3} \mathrm{~V}_{2} \mathrm{O}_{8}+\mathrm{Na}_{2} \mathrm{O}
\end{aligned}
$$

Through which, the metallic oxides are dissolved. XRD results evidence the formation of these metallic vanadates. Table 2 presents the melting points of the metallic vanadates formed during the dissolution of the corresponding metallic oxides in presence of $\mathrm{NaVO}_{3}$. Taking into account these temperatures, it is possible to explain the best performance of nickel in $\mathrm{NaVO}_{3}$ molten salt, since $\mathrm{Ni}_{3} \mathrm{~V}_{2} \mathrm{O}_{8}$ is a refractory compound which reduces the corrosivity of the vanadium molten salt, by effect of the increase in the melting point of the salt [27].

The corrosive aggressiveness of $\mathrm{NaVO}_{3}$ is due to its low melting point, being this of $650^{\circ} \mathrm{C}[28,29]$. The fluidity of this compound produces that species in molten salt have major interaction between them and the electrochemical and chemical reactions are carried out more quickly. Nevertheless, the presence of $\mathrm{Ni}_{3} \mathrm{~V}_{2} \mathrm{O}_{8}$ obviously reduces the fluidity of the initially pure $\mathrm{NaVO}_{3}[30,31]$. Additionally, the species $\mathrm{Ni}_{2} \mathrm{~V}_{2} \mathrm{O}_{7}$, which has a larger melting point with respect to that for $\mathrm{NaVO}_{3}$, also produces a decrease in the fluidity of the molten salt. Whereas in the systems where pure chromium and pure iron are corroding, the melting points are smaller, so that the corrosion rate is expected to be alike and bigger than that of pure nickel. 


\section{Conclusions}

According to the results and discussion, it is possible to conclude that pure nickel presented the best corrosion performance, which was presumably due to the formation of the species $\mathrm{Ni}_{3} \mathrm{~V}_{2} \mathrm{O}_{8}$, which induced a lower fluidity of the molten salt, and therefore smaller corrosion rates. LPR technique confirms this result, in which iron and then chromium present the major corrosion rates. For the particular case where severe pitting corrosion with high pitting density (a lot of small pits) is seen, like what was observed in pure chromium, the conventional weight loss method is not reliable, since, corrosion products could keep inside the pits; therefore an underestimated corrosion rate may be determined. Also, physical characterization showed that even though chromium and nickel suffered pitting corrosion, the presence of much larger cathodic areas in nickel should induce smaller corrosion rates; since, these areas present a uniform corrosion process with small corrosion rates. Potential measurements also indicated the best performance of nickel, in which the corrosion potential is nobler than that of chromium and iron after 55 hours of exposure. Before 55 hours, the corrosion potential of nickel was smaller than that of $\mathrm{Cr}$ and $\mathrm{Fe}$, which must be due to nucleation and formation of pits. Also, the poor performance of iron was due to the way in which this material was attacked, resulting in a severe intergranular corrosion process with the following grain dropping.

\section{Conflict of Interests}

The authors declare that there is no conflict of interests regarding the paper content and the publication of this paper.

\section{Acknowledgment}

Authors gratefully thank Conacyt for the support to the student Oscar Sotelo-Mazón to carry out his doctoral project at Morelos State University.

\section{References}

[1] T. S. Sidhu, S. Prakash, and R. D. Agrawal, "Hot corrosion and performance of nickel-based coatings," Current Science, vol. 90, no. 1, pp. 41-47, 2006.

[2] Y.-S. Hwang and R. A. Rapp, "Thermochemistry and solubilities of oxides in sodium sulfate-vanadate solutions," Corrosion, vol. 45, no. 11, pp. 933-937, 1989.

[3] R. A. Rapp, "Hot corrosion of materials: a fluxing mechanism?" Corrosion Science, vol. 44, no. 2, pp. 209-221, 2002.

[4] Y. Harada, S. Naito, T. Tsuchiya, and Y. Nakajima, "Problems of low grade oil firing boilers and their solutions," Mitsubishi Technical Bulletin 85, 1981.

[5] T. Kawamura and Y. Harada, "Control of gas side corrosion in oil fired boiler," Mitsubishi Technical Bulletin 139, 1980.

[6] H. W. Halstead, "Some chemical aspects of fireside corrosion in oil-fired boilers," Journal of the Institute of Fuel, vol. 43, no. 354, pp. 234-239, 1970.
[7] A. Wong-Moreno and R. I. Marchan Salgado, "Molten salt corrosion of heat resisting alloys," in Proceedings of the NACE International Annual Conference and Corrosion Show (Corrosion '95), paper 465, pp. 1-16, NACE International, Houston Tex, USA, 1995.

[8] R. A. Rapp and Y. S. Zhang, "Hot corrosion of materialsfundamental aspects, molten salt forum," in Transactions Technological Publications, vol. 5-6, pp. 25-38, 1998.

[9] L. D. Paul and R. R. Seeley, "Oil ash corrosion-a review of utility boiler experience," in Proceedings of the International Annual Conference and Corrosion Show (Corrosion '90), paper 267, pp. 1-12, Houston, Tex, USA, 1990.

[10] A. Wong-Moreno, Y. Mujica Martínez, and L. Martínez, "High temperature corrosion enhanced by residual fuel oil ash deposits," in Proceedings of the International Annual Conference and Corrosion Show (Corrosion '94), paper 185, pp. 1-18, NACE International, 1994.

[11] K. Natesan, "Corrosion-erosion behavior of materials in a coalgasification environment," Corrosion, vol. 32, no. 9, pp. 364-370, 1976.

[12] J. G. Gonzalez-Rodriguez, S. Haro, A. Martinez-Villafañe, V. M. Salinas-Bravo, and J. Porcayo-Calderon, "Corrosion performance of heat resistant alloys in $\mathrm{Na}_{2} \mathrm{SO}_{4}-\mathrm{V}_{2} \mathrm{O}_{5}$ molten salts," Materials Science and Engineering A, vol. 435-436, pp. 258-265, 2006.

[13] H. Singh, D. Puri, and S. Prakash, "An overview of $\mathrm{Na}_{2} \mathrm{SO}_{4}$ and/or $\mathrm{V}_{2} \mathrm{O}_{5}$ induced hot corrosion of $\mathrm{Fe}$ - and Ni-based superalloys," Reviews on Advanced Materials Science, vol. 16, no. 1-2, pp. 27-50, 2007.

[14] T. Tzvetkoff and P. Gencheva, "Mechanism of formation of corrosion layers on nickel and nickel-based alloys in melts containing oxyanions-a review," Materials Chemistry and Physics, vol. 82, no. 3, pp. 897-904, 2003.

[15] C. Cuevas-Arteaga, J. Uruchurtu-Chavarín, J. PorcayoCalderon, G. Izquierdo-Montalvo, and J. Gonzalez, "Study of molten salt corrosion of HK-40m alloy applying linear polarization resistance. And conventional weight loss techniques," Corrosion Science, vol. 46, no. 11, pp. 2663-2679, 2004.

[16] C. Cuevas-Arteaga, J. Uruchurtu-Chavarín, J. González, G. Izquierdo-Montalvo, J. Porcayo-Calderón, and U. CanoCastillo, "Corrosion evaluation of Alloy 800 in sulfate/vanadate molten salts," Corrosion, vol. 60, no. 6, pp. 548-560, 2004.

[17] "Practice for Laboratory immersion corrosion testing of metals," ASTM Standard G31, 1995.

[18] "Practice for preparing, cleaning, and evaluating corrosion test specimens," ASTM Standard G1, 1994.

[19] L. G. Berry, Ed., Powder Diffraction Data File-Inorganic Phases, Publication of the Joint Committee on Powder Diffraction Standards, Centre for Diffraction Data, Swarthmore, Pa, USA.

[20] R. Baboian, S. Dean, H. Hack, G. Haynes, J. Scully, and D. O. Sprowls, Corrosion Tests and Standards: Application and Interpretation, ASTM Manual Series, MNL20, ASTM, Philadelphia PA, USA, 1995.

[21] J. R. Wilson, "Understanding and preventing fuel ash corrosion," in Proceedings of the International Annual Conference and Corrosion Show (Corrosion '76), paper 12, pp. 1-23, 1976.

[22] L. B. Pfeil, "Corrosion of heat-resisting alloys in the presence of fuel-oil ash," British Petroleum Equipment News, vol. 7, no. 4-5, pp. 54-69, 1957. 
[23] D. A. Pantony and K. I. Vasu, "Studies in the corrosion of metals under melts-III. Kinetics of the corrosion of pure metals under molten vanadium pentoxide," Journal of Inorganic and Nuclear Chemistry, vol. 30, no. 3, pp. 755-779, 1968.

[24] I. Gurrappa, "Identification of hot corrosion resistant MCrAlY based bond coatings for gas turbine engine applications," Surface and Coatings Technology, vol. 139, no. 2-3, pp. 272-283, 2001.

[25] Y. van Ingelgem, I. Vandendael, D. van den Broek, A. Hubin, and J. Vereecken, "Influence of laser surface hardening on the corrosion resistance of martensitic stainless steel," Electrochimica Acta, vol. 52, no. 27, pp. 7796-7801, 2007.

[26] Y.-S. Hwang and R. A. Rapp, “Thermochemistry and solubilities of oxides in sodium sulfate-vanadate solutions," Corrosion, vol. 45, no. 11, pp. 933-937, 1989.

[27] E. Rocca, L. Aranda, M. Moliere, and P. Steinmetz, "Nickel oxide as a new inhibitor of vanadium-induced hot corrosion of superalloys-comparison to MgO-based inhibitor," Journal of Materials Chemistry, vol. 12, no. 12, pp. 3766-3772, 2002.

[28] Y. Harada, S. Naito, T. Tsuchiya, and Y. Nakajima, "Problems of low grade oil firing boilers and their solutions," in Mitsubishi Technical Bulletin, pp. 85-95, 1981.

[29] P. A. Alexander and R. A. Marsden, "Corrosion of superheater materials by residual oil ash," in Proceedings of the International Conference on the mechanism of corrosion by fuel impurities, L. M. Wyatt and G. J. Evans, Eds., pp. 542-555, Butterworths, Marchwood, UK, 1963.

[30] G. W. Cunningham and A. de S. Brasunas, "The effects of contamination by vanadium and sodium compounds on the aircorrosion of stainless steel," Corrosion National Association of Corrosion Engineers, vol. 12, pp. 389t-405t, 1956.

[31] H. Lewis, "Corrosion by vanadium-pentoxide sodium-sulphate mixtures in laboratory tests: correlation with corrosion by oilash in field tests," British Petroleum Equipment News, vol. 7, no. 4-5, pp. 17-23, 1957. 

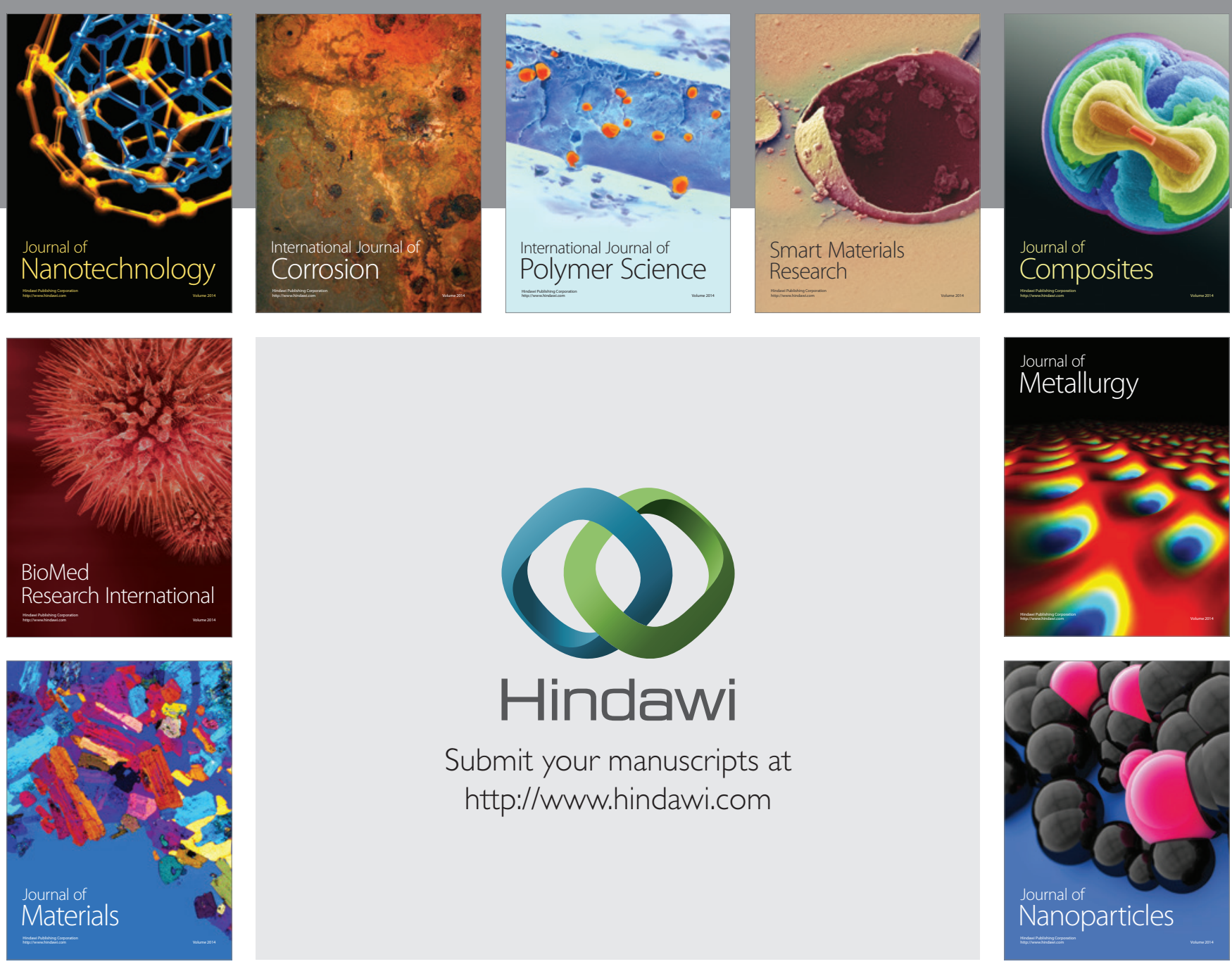

Submit your manuscripts at http://www.hindawi.com
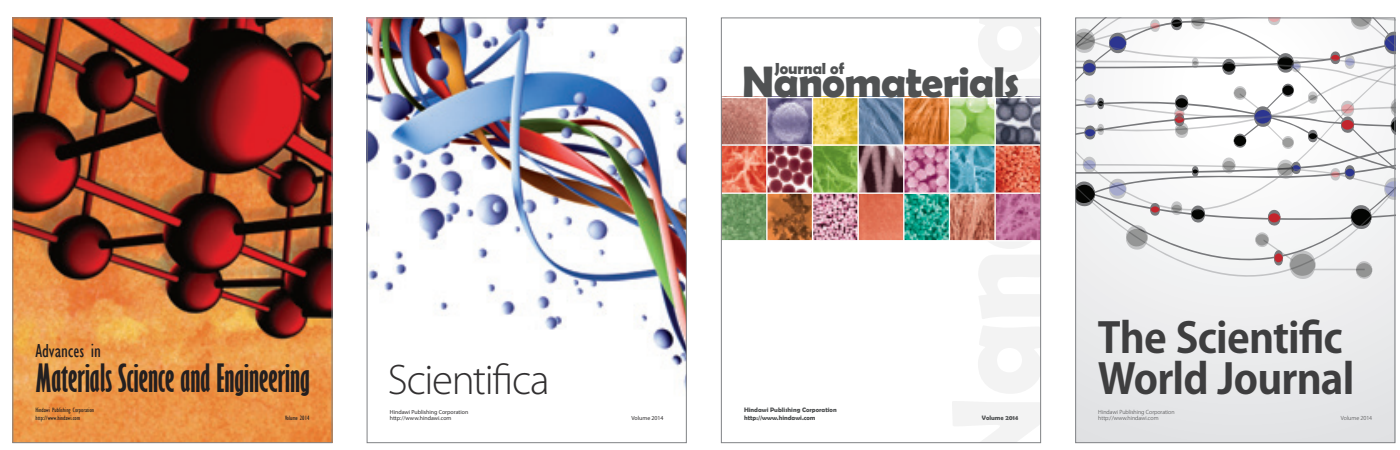

\section{The Scientific World Journal}
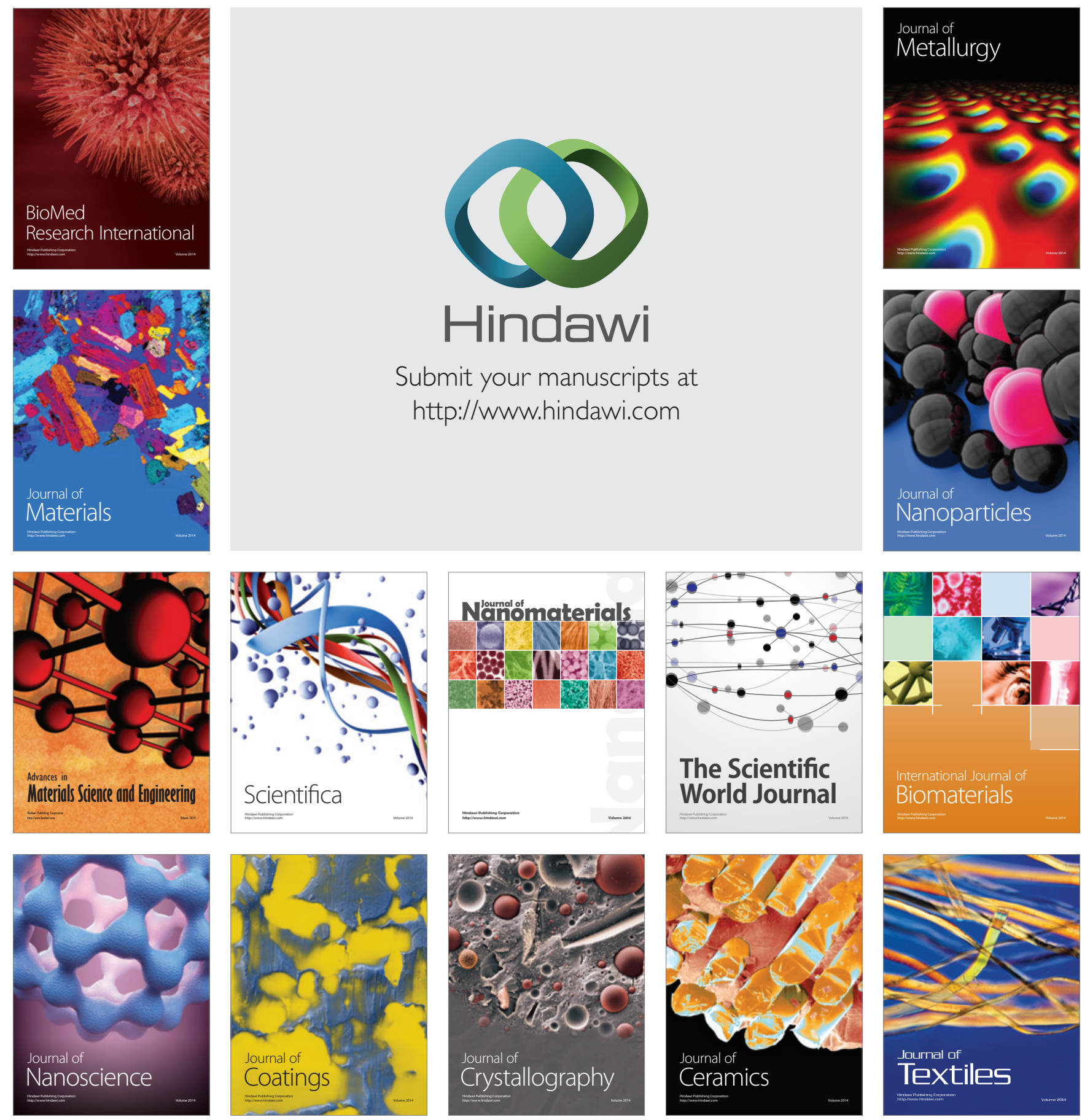